\title{
RENAL FUNCTION AND THE AZOTEMIA FOLLOWING HEMATEMESIS ${ }^{1,2}$
}

\author{
By RICHARD J. STEVENS, ${ }^{8}$ LEON SCHIFF, ANNA LUBLIN, AND ELLEN S. GARBER \\ (From the Department of Internal Medicine, University of Cincinnati Medical School, \\ and the Gastric Laboratory, Cincinnati General Hospital, Cincinnati)
}

(Received for publication September 11, 1939)

Elevation of the blood urea nitrogen following massive hemorrhage from the stomach and duodenum is a frequent occurrence (1). Its mechanism is not the same as that associated with high intestinal obstruction, as it occurs in the absence of any vomiting (2) (e.g. in the presence of melena alone ${ }^{4}$, and is associated with a normal or increased blood chloride concentration $(3,4$, 5 ) and a normal carbon dioxide combining power of the blood $(4,5)$. The factors contributing to this increase of the urea nitrogen content of the blood have been said to comprise shock, dehydration, starvation, renal insufficiency, and absorption of decomposition products of the blood liberated in the intestinal tract. We have elsewhere adduced evidence which excludes the factors of shock, dehydration, and starvation as essential but which emphasizes the importance of the digestion of the blood in the intestinal tract $(1,6)$.

Attempts have previously been made to evaluate the renal factor in this increase of the blood urea nitrogen. Sanguinetti (7) found that three patients with elevated blood urea content following hematemesis were able to excrete a concenration of 30 to 38 grams of urea per liter of urine and believed that this excluded renal insufficiency. Christiansen (2) reported normal kidneys at necropsy in a case of hematemesis (due to peptic ulcer) in which there was an abnormally high blood urea concentration. Ingegno (8) emphasized the presence of normal blood pressure, high urine specific gravity, and negative urinary find-

\footnotetext{
1 Part of a paper presented by title before the American Society for Clinical Investigation, May, 1939.

2 This work was aided by a grant from the Union Central Life Insurance Company.

3 Justin A. Rollman Fellow in Internal Medicine, 19381939.

4 We have observed increase in the blood urea nitrogen in four of eight patients with melena only included in a series of fifty-three cases of hematemesis and melena (1).
}

ings in his patients with elevated blood urea nitrogen. In a fatal case of hematemesis with a blood urea concentration of $216 \mathrm{mgm}$. per cent, Alsted (9) observed a fall in the urea clearance to 15 per cent of normal in the presence of organically normal kidneys. He felt that the reduction of renal function was secondary to the lowering of the arterial blood pressure resulting from the hemorrhage. In four other patients displaying less marked azotemia (blood urea values of 42 , 51,58 , and $59 \mathrm{mgm}$. per cent), there was no reduction of the urea clearance. Clausen (10) reported a reduction of urea clearance in three cases, though not sufficient to account for the azotemia. ${ }^{5}$

In five patients with increased blood urea content following hematemesis, Borst (4) found a normal urea clearance in two and a reduction to 19,47 , and 58 per cent respectively in the remaining three. In another group of three patients with shock he found the urea clearance reduced to 10 per cent or less of the normal (3), presumably as a result of the shock. In a series of twelve patients with hematemesis Black (14) recently reported urea clearances of 38 to 47 per cent in four, 59 to 65 per cent in three, and 75 to 125 per cent in the remaining five. When the clearances were again determined one week later, there was a rise to 87 per cent or more in three of the four cases having an initial value of 38 to 47 per cent and to 65 per cent in the fourth. In the three cases with initial values of 59 to 65 per cent, there was no significant change in two and a reduction from 60 to 37 per cent in the third.

\footnotetext{
5 According to Chasis and Smith (11), a drop in the urea clearance from 100 to 90 per cent will increase the blood urea by 10 per cent, etc., but an increase of 10 per cent is not ordinarily detectable because of variations in protein intake and variations in urea clearance incidental to oliguria versus diuresis. According to Peters and Van Slyke (12) and Smith (13), it is only when the urea clearance is reduced to 20 per cent of normal that the blood urea nitrogen becomes definitely elevated, irrespective of these other factors.
} 
Black believes that his evidence " is insufficient to establish definitely the mechanism of renal impairment" and that "the fall in urea clearance appears to have some relation to the red cell volume per kilogramme of body weight." Witts (5) believes that the increase in the blood urea is due to the fall in the blood volume and the blood flow through the kidneys at a time when the kidneys have the extra work of excreting a large amount of nitrogen derived from the blood in the intestine.

In addition to the urea clearance we have determined the phenol red and inulin clearances in four patients with hematemesis and elevated blood urea nitrogen but without shock or obvious kidney disease. The determinations were made shortly after admission to the Cincinnati General Hospital and were repeated when the blood urea nitrogen was normal.

\section{METHODS}

The method used was that recommended by Smith et al (15), and consisted of a rapid intravenous infusion of normal saline containing inulin and phenol red given for about ten minutes as a priming dose, after which a more dilute solution (usually about 8 per cent) was infused at the rate of $4 \mathrm{cc}$. per minute throughout the period of observation which usually lasted an hour and a half. The urine was collected from the bladder by an inlying catheter, being allowed to drain into a narrow-necked flask during individual collection periods which varied from ten to twenty minutes. A few minutes before the end of each urine collection period the bladder was washed out with a known amount of distilled water and the wash fluid was expelled by insufflation of air. The urine and wash fluid were combined for analysis, and a preliminary 1:10 dilution was made at once to prevent precipitation of the inulin. Blood samples were usually drawn from the antecubital vein (1) before the infusion was started, (2) after the bladder was first washed just prior to beginning the first urine collection period, (3) after the second collection period, and (4) at the end of the last collection period. Double strength colorless heparin was used to prevent clotting. The blood was centrifuged at once, the plasma separated, and an accurately measured 2 cc. sam- ple set aside for inulin analysis. Oxalate was added to the rest of the plasma for urea and phenol red determinations. The urea was determined on the plasma and urine by the aeration method of Van Slyke and Cullen (16). The inulin and phenol red determinations were carried out according to the method of Smith and associates (15). All samples were determined in duplicate. The several plasma concentrations were plotted against time and the precise values at the middle of each urine collection period were determined by interpolation. All clearances were corrected to a body surface area of 1.73 square meters at the suggestion of Smith (17).

According to Smith (13), the inulin clearance is a measure of glomerular filtration and in normal man averages about $120 \mathrm{cc}$. per minute, while the phenol red clearance is a measure of tubular function and has an average normal value of 400 cc. per minute. The phenol red clearance is an index of renal blood flow. The effective renal blood flow may be calculated approximately from the phenol red clearance and hematocrit by using the average phenol red/diodrast clearance ratio of 0.56 as reported by Smith, Goldring, and Chasis (15), and normally averages about 1400 cc. per minute.

\section{CASE STUDIES}

\section{Clinical history, case 1}

C. F., Number 106697, white male, age 53, entered the Cincinnati General Hospital November 4, 1938. He had been treated for diabetes at this hospital for several years. Eight hours before admission, immediately following his evening meal, he vomited about a pint of bright blood. At 11 p.m. he vomited about one pint of dark, partly clotted blood following which he became dizzy and faint and was sent to the hospital.

The pulse was 104; the blood pressure was $122 / 60$. Free fluid was present in the peritoneal cavity and the spleen was palpable. The left leg had previously been amputated at the mid-thigh.

Hemoglobin 6.6 grams per $100 \mathrm{cc}$; red blood count $2,600,000$; white blood count 9,500. The urine contained a trace of albumin, a two plus test for sugar, and a one plus test for acetone. The stools were tarry and chemical tests for blood were strongly positive. The blood urea nitrogen was $50 \mathrm{mgm}$. per cent, the blood sugar $351 \mathrm{mgm}$. per cent, and the carbon dioxide combining power 49 volume per cent.

On the second hospital day when the blood urea nitrogen was $37 \mathrm{mgm}$. per cent and the blood pressure was $125 / 75$, kidney function tests were done and found to be 
TABLE I

Summary of urea, inulin, and phenol red clearances in case 1

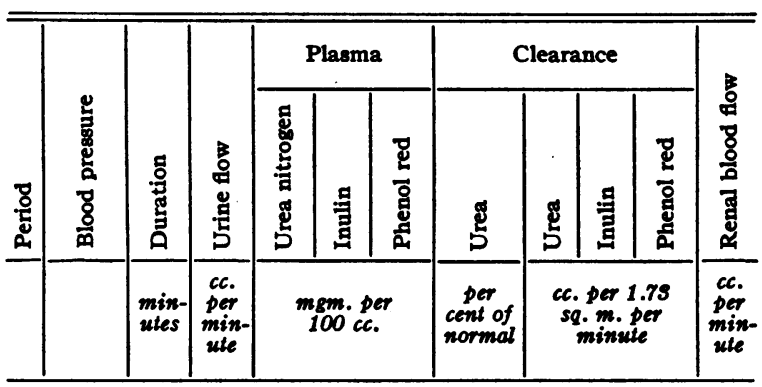

OBSERVATIONS ON NOVEMBBER 5, 1938

\begin{tabular}{l|l|l|l|l|l|l|l|l|l|l|l|l}
\hline 1 & $125 / 75$ & 14 & 4.93 & 37 & 111 & 0.91 & 143 & 107 & 140 & 536 & 1200 \\
2 & $120 / 75$ & 14 & 4.43 & 37 & 109 & 0.88 & 119 & 89 & 121 & 460 & 1038 \\
3 & $125 / 75$ & 14 & 5.31 & 36 & 107 & 0.84 & 134 & 101 & 142 & 532 & 1207 \\
4 & $128 / 72$ & 20 & 6.05 & 35 & 103 & 0.80 & 129 & 97 & 139 & 532 & 1207 \\
\hline
\end{tabular}

above the average normal (Table I). The patient died on his fourth hospital day at which time the blood urea nitrogen was $17 \mathrm{mgm}$. per cent. Hepatic cirrhosis and a ruptured esophageal varix were found at necropsy.

\section{Clinical history, case 2}

H. B., Number 101434, white male, age 55, entered the Cincinnati General Hospital August 18, 1938, six hours following the vomiting of what he estimated to be a quart of bright blood. He had had three previous episodes of bleeding from the gastro-intestinal tract in the preceding four years. In 1931 he had been found to have a perforated duodenal ulcer.

Upon admission the pulse was 96 , the blood pressure $152 / 80$. The hemoglobin was 9.8 grams per $100 \mathrm{cc}$; red blood count $3,600,000$. The urinalysis was normal. His stool was liquid tarry, and gave a strongly positive chemical test for blood. The blood urea nitrogen was $24 \mathrm{mgm}$. per cent, the plasma chlorides $546 \mathrm{mgm}$. per cent.

Following another bout of hematemesis on the third hospital day, the blood urea nitrogen was $40 \mathrm{mgm}$. per cent. Kidney function tests were done at this time and were repeated ten days later (Table II). The urea and phenol red clearances, when first determined, were moderately decreased; the inulin clearance was normal, and the renal blood flow was diminished. The urea clearance, however, was not sufficiently reduced to account for the elevated blood urea nitrogen. Ten days later, the urea clearance was normal although the inulin clearance was definitely reduced and the phenol red clearance less than on the first determination. The discrepancy between the urea and inulin clearances was not explained.

\section{Clinical history, case 3}

C. K., Number 101015, white male, age 62, entered the Cincinnati General Hospital on August 9, 1938. Two days before admission he suddenly experienced vague epigastric discomfort followed by the vomiting of a large
TABLE II

Summary of urea, inulin, and phenol red clearances in case 2

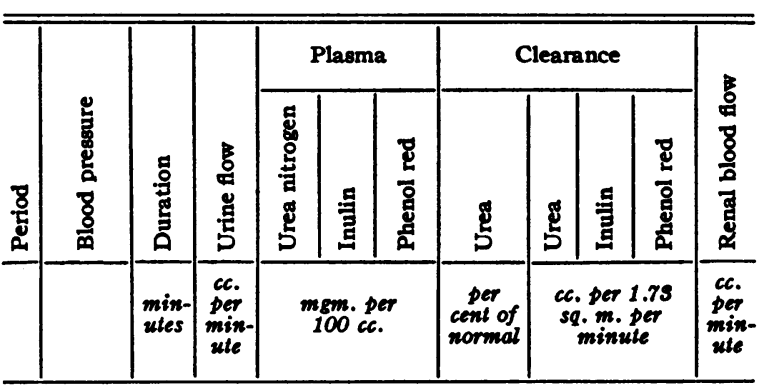

OBSERVATIONS ON AUGUST 20, 1938

\begin{tabular}{l|l|l|l|l|l|l|l|l|l|l|l|l}
\hline 1 & $128 / 70$ & 15 & 0.94 & 35.6 & 100 & 1.05 & 64 & 34 & 130 & 347 & 775 \\
2 & $125 / 72$ & 16 & 0.67 & 35.4 & 100 & 1.04 & 64 & 34 & 109 & 327 & 730 \\
3 & $124 / 76$ & 15 & 0.77 & 35.4 & 100 & 1.02 & 70 & 38 & 128 & 355 & 790 \\
4 & $120 / 80$ & 15 & 0.60 & 35.4 & 100 & 1.00 & 76 & 41 & 109 & 338 & 752 \\
\hline
\end{tabular}

OBSERVATIONS ON AUGUSt 30, 1938

\begin{tabular}{r|r|r|r|r|r|r|r|r|r|r|r}
\hline 1 & $130 / 80$ & 16 & 1.62 & 9.3 & 122 & 1.16 & 81 & 43 & 82 & 273 & 677 \\
2 & $128 / 76$ & 17 & 1.18 & 8.6 & 128 & 1.20 & 98 & 53 & 80 & 259 & 641 \\
3 & $130 / 80$ & 17 & 1.11 & 8.0 & 133 & 1.26 & 98 & 53 & 83 & 271 & 672 \\
4 & $132 / 82$ & 17 & 1.23 & 8.7 & 150 & 1.33 & 101 & 55 & 76 & 249 & 618 \\
\hline
\end{tabular}

amount of clotted blood. On the day of admission he vomited dark blood several times.

The pulse was 88 . The blood pressure was $90 / 40$ but rose soon afterwards to $118 / 50$. The abdomen was negative.

TABLE III

Summary of urea, inulin, and phenol red clearances in case 3

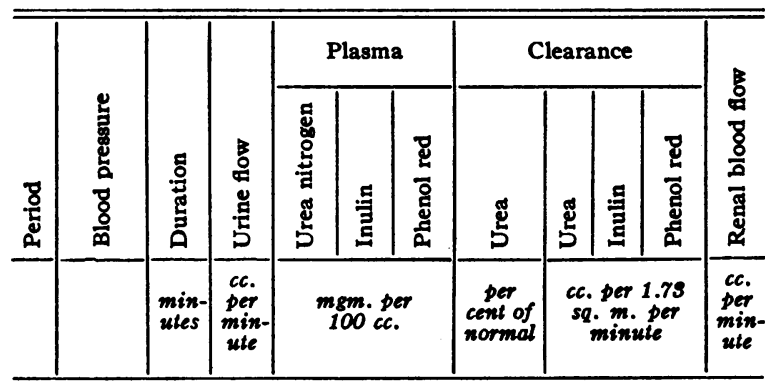

OBSERVATIONS ON AUGUST 9, 1938

\begin{tabular}{l|l|l|l|l|l|l|l|l|l|l|l|l}
\hline 1 & $118 / 50$ & 12 & 0.58 & 38 & 136 & 1.01 & 75 & 40 & 48 & 228 & 486 \\
2 & & 12 & 0.58 & 38 & 143 & 1.02 & 55 & 31 & 48 & 221 & 472 \\
3 & $120 / 55$ & 13 & 0.69 & 38 & 150 & 1.05 & 57 & 30 & 55 & 233 & 498 \\
4 & & 11 & 0.72 & 39 & 150 & 1.05 & 59 & 33 & 54 & 233 & 498 \\
5 & $124 / 58$ & 10 & 0.70 & 40 & 150 & 1.05 & 45 & 25 & 51 & 225 & 479 \\
\hline
\end{tabular}

OBSERVATIONS ON AUGUST 23, 1938

\begin{tabular}{l|l|l|l|l|l|l|l|l|l|l|l|l}
\hline 1 & $128 / 50$ & 15 & 2.0 & 12 & 105 & 0.9 & 43 & 32 & 74 & 236 & 542 \\
2 & & 15 & 2.7 & 12 & 110 & 1.0 & 93 & 70 & 80 & 252 & 580 \\
3 & $128 / 50$ & 15 & 1.9 & 13 & 150 & 1.0 & 58 & 44 & 71 & 220 & 506 \\
4 & & 15 & 1.4 & 13 & 120 & 1.0 & 54 & 28 & 70 & 232 & 530 \\
5 & $128 / 50$ & 11 & 1.4 & 14 & 140 & 1.1 & 48 & 26 & 67 & 256 & 579 \\
\hline
\end{tabular}

The hemoglobin was 5.8 grams per 100 cc.; red blood count $1,800,000$. The urine was normal. The stools were tarry, and the guaiac test for blood was strongly positive. The blood urea nitrogen on admission was 40 
mgm. per cent, carbon dioxide combining power 52 volume per cent, and the plasma chloride $564 \mathrm{mgm}$. per cent.

Kidney function tests were done shortly after admission and again on the fourteenth hospital day when the blood urea nitrogen was $13 \mathrm{mgm}$. per cent (Table III). There was a reduction of all the clearances and a decrease in the effective renal blood flow. The decrease in the urea clearance, however, was not sufficient to account for the elevated blood urea content. Fourteen days later there was no significant change in renal function or in the effective renal blood flow although the blood urea nitrogen was normal.

\section{Clinical history, case 4}

W. B., Number 106702, white male, age 57, entered the Cincinnati General Hospital on November 4, 1938. He had had two episodes of hematemesis in the past and had been found to have a hypertrophic gastritis. The night before admission he suddenly vomited a large amount of blood. This was followed by the passage of three liquid dark red stools. Shortly after admission he again vomited a large amount of dark clotted blood.

The pulse was 100 , his blood pressure $115 / 70$. The hemoglobin was 8.8 grams per $100 \mathrm{cc}$; red blood count $2,700,000$. The urinalysis was normal. The stools were tarry and gave a strongly positive test for occult blood. The blood urea nitrogen was $41 \mathrm{mgm}$. per cent and the carbon dioxide combining power of the blood 56 volume per cent.

TABLE IV

Summary of urea, inulin, and phenol red clearances in case 4

\begin{tabular}{|c|c|c|c|c|c|c|c|c|c|c|c|}
\hline \multirow{3}{*}{ 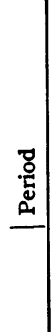 } & \multirow[b]{2}{*}{ 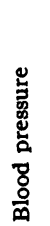 } & \multirow[b]{2}{*}{ مَّ } & \multirow[b]{2}{*}{ 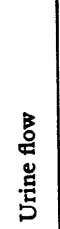 } & \multicolumn{3}{|c|}{ Plasma } & \multicolumn{4}{|c|}{ Clearance } & \multirow{2}{*}{ 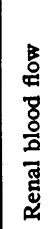 } \\
\hline & & & & 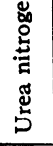 & $\stackrel{\Xi}{\Xi}$ & 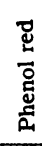 & $\begin{array}{l}\text { 刃 } \\
5\end{array}$ & 岕 & 豆 & 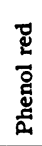 & \\
\hline & & $\begin{array}{l}\min - \\
\text { utes }\end{array}$ & $\begin{array}{c}c c . \\
\text { per } \\
\text { min- } \\
\text { ute }\end{array}$ & \multicolumn{3}{|c|}{$\begin{array}{l}\text { mgm. per } \\
100 \text { cc. }\end{array}$} & $\begin{array}{l}\text { per } \\
\text { cent of } \\
\text { normal }\end{array}$ & \multicolumn{3}{|c|}{$\begin{array}{c}c c . \text { per } 1.79 \\
\text { sq. m. per } \\
\text { minute }\end{array}$} & $\begin{array}{l}c c . \\
\text { per } \\
\text { min- } \\
\text { ute }\end{array}$ \\
\hline
\end{tabular}

OBSERVATIONS ON NOVEMBER 5,1938

\begin{tabular}{l|l|l|l|l|l|l|l|l|l|l|l}
\hline 1 & $120 / 68$ & 20 & 3.25 & 63.9 & 140 & 1.06 & 50 & 37 & 82.4 & 356 & 836 \\
2 & $118 / 70$ & 16 & 3.81 & 64.0 & 158 & 1.15 & 53 & 40 & 74.0 & 302 & 701 \\
3 & $122 / 70$ & 12 & 4.00 & 64.1 & 193 & 1.31 & 59 & 46 & 78.2 & 377 & 888 \\
\hline
\end{tabular}

OBSERVATIONS ON NOVEMBER 8,1938

\begin{tabular}{r|r|r|r|r|r|r|r|r|r|r|r}
\hline 1 & $148 / 70$ & 14 & 1.7 & 14.6 & 129 & 0.74 & 47 & 31 & 100.0 & 355 & 790 \\
2 & $145 / 70$ & 15 & 1.8 & 14.8 & 137 & 0.79 & 42 & 33 & 95.0 & 371 & 829 \\
3 & $145 / 70$ & 11 & 2.0 & 15.2 & 145 & 0.84 & 67 & 52 & 97.0 & 421 & 989 \\
4 & $140 / 70$ & 10 & 2.4 & 15.7 & 152 & 0.88 & 73 & 54 & 99.0 & 462 & 1030 \\
\hline
\end{tabular}

Four hours after admission the blood urea nitrogen had risen to $64 \mathrm{mgm}$. per cent. Kidney function studies were done at this time and again three days later when his blood urea nitrogen was $15 \mathrm{mgm}$. per cent. The results are shown in Table IV. While there was a reduction of all the clearances and of the effective renal blood flow, the decrease in the urea clearance was not sufficient to account for the elevated blood urea nitrogen. Three days later, when the blood urea nitrogen was normal, there was no significant difference in renal function or in the effective renal blood flow.

According to Peters and Van Slyke (12), any reduction of the urea clearance is due either to decreased renal blood flow or to less complete extraction of urea from the blood. It is possible that reduction of renal blood flow played a rôle in reducing the clearances in three of our cases but to an extent not sufficient to account for the elevated blood urea nitrogen.

It has been suggested that toxic products arising from the decomposition of the blood which is liberated in the intestines following hematemesis and melena may lead to impairment of kidney function and thus account for elevation of the blood urea nitrogen (18). To exclude such a factor, the kidney function tests were carried out in five individuals two days before and eighteen hours after intragastric administration of 2,000 cc. of citrated blood. ${ }^{6}$ The five subjects included Cases 2 and 3 and, in addition, three males (free

TABLE $V$

Renal function before and eighteen hours after beginning intragastric administration of 2,000 cc. of blood

\begin{tabular}{|c|c|c|c|c|c|c|c|c|}
\hline \multirow{3}{*}{$\begin{array}{l}\text { Case } \\
\text { num- } \\
\text { ber }\end{array}$} & \multicolumn{4}{|c|}{ Before blood administration } & \multicolumn{4}{|c|}{ After blood administration } \\
\hline & \multirow{2}{*}{$\begin{array}{c}\text { Blood } \\
\text { urea } \\
\text { nitro- } \\
\text { gen }\end{array}$} & \multicolumn{3}{|c|}{ Clearances } & \multirow{2}{*}{$\begin{array}{c}\text { Blood } \\
\text { urea } \\
\text { nitro- } \\
\text { gen }\end{array}$} & \multicolumn{3}{|c|}{ Clearances } \\
\hline & & Urea & Inulin & $\begin{array}{c}\text { Phenol } \\
\text { red }\end{array}$ & & Urea & Inulin & $\begin{array}{c}\text { Phenol } \\
\text { red }\end{array}$ \\
\hline & 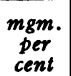 & $\begin{array}{l}\text { per } \\
\text { cent of } \\
\text { normal }\end{array}$ & \multicolumn{2}{|c|}{$\begin{array}{c}\text { cc. per } 1.7 s \\
\text { sq. m. per } \\
\text { minute }\end{array}$} & $\begin{array}{c}\text { mgm. } \\
\text { per } \\
\text { cent }\end{array}$ & $\begin{array}{l}\text { per } \\
\text { cent of } \\
\text { normal }\end{array}$ & \multicolumn{2}{|c|}{$\begin{array}{c}\text { cc. per } 1.73 \\
\text { sq. m. per } \\
\text { minute }\end{array}$} \\
\hline $\begin{array}{l}2 \\
3 \\
5 \\
6 \\
7\end{array}$ & $\begin{array}{l}13 \\
13 \\
11 \\
12 \\
14\end{array}$ & $\begin{array}{r}72 \\
54 \\
103 \\
88 \\
113\end{array}$ & $\begin{array}{r}87 \\
74 \\
99 \\
106 \\
117\end{array}$ & $\begin{array}{l}283 \\
239 \\
281 \\
363 \\
316\end{array}$ & $\begin{array}{l}37 \\
51 \\
35 \\
26 \\
54\end{array}$ & $\begin{array}{r}70 \\
54 \\
74 \\
81 \\
108\end{array}$ & $\begin{array}{r}83 \\
76 \\
122 \\
116 \\
128\end{array}$ & $\begin{array}{l}268 \\
252 \\
337 \\
339 \\
348\end{array}$ \\
\hline
\end{tabular}

of obvious kidney disease) aged 19, 29, and 50 respectively. Two of the three had had a recent hematemesis, while the third was suffering from optic atrophy. The results show that no significant change in renal function occurred (Table V).

6 The blood, which was previously stored in the blood bank for three weeks, was given by stomach tube in doses of 700,700 , and $600 \mathrm{cc}$. at four-hour intervals. Following introduction of the blood, there was a distinct rise in the blood urea nitrogen reaching a maximum twenty hours after the first dose was given (6). 


\section{SUMMARY AND CONCLUSION}

The urea, inulin, and phenol red clearances may be either normal or reduced in the presence of the increased blood urea nitrogen content which follows hematemesis. The reduction in the urea clearance may be due to the decreased renal blood flow but is insufficient to account for the increased blood urea content and persists in spite of the return of the blood urea nitrogen to normal.

The elevation of the blood urea nitrogen content which follows hematemesis in the absence of shock is not due to impairment of kidney function.

We wish to thank Professor Homer W. Smith for the collaboration of Miss Anna Lublin and for his criticism and advice.

\section{BIBLIOGRAPHY}

1. Schiff, L., and Stevens, R. J., Elevation of the urea nitrogen content of the blood following hematemesis or melena. (A review of the literature is included.) Arch. Int. Med., 1939, 64, 1239.

2. Christiansen, T., Uraemia as cause of death in massive haemorrhage from peptic ulcer. Acta med. Scandinav., 1935, 85, 333.

3. Borst, J. G. G., The cause of hyperchloremia and hyperazotemia in patients with recurrent massive hemorrhage from peptic ulcer. Acta med. Scandinav., 1938, 97, 68.

4. Borst, J. G. G., Uber Erhöhung des Kochsalz-und Harnstoffgehaltes und Erniedrigung des Albumingehaltes des Blutes bei Patienten mit starken Magenblutungen. Ztschr. f. klin. Med., 1936, 130, 74.

5. Witts, L. J., Haematemesis and melaena. Brit. M. J., 1937, $1,847$.
6. Schiff, L., Stevens, R. J., Goodman, S., Garber, E., and Lublin, A., Observations on the oral administration of citrated blood in man. I. The effects on the blood urea nitrogen. Am. J. Digest. Dis. and Nutrition, 1939, 6, 597.

7. Sanguinetti, L. V., Azoemias en el curso de las hemorragias retenidas a nivel del tubo digestivo (estudio clinico y experimental). Arch. argent. de enferm. d. ap. digest. y de la nutrición, 1934, 9, 264.

8. Ingegno, A. P., The elevated blood urea of acate gastrointestinal hemorrhage and its significance. Am. J. M. Sc., 1935, 190, 770.

9. Alsted, G., Further studies on azotemia following hemorrhage in the digestive tract. Am. J. M. Sc., 1936, 192, 199.

10. Clausen, J., Hyperazotemia in cases of acute ventricle hemorrhage. Acta med. Scandinav., 1936, Supp. 78, 908.

11. Chasis, H., and Smith, H. W., The excretion of urea in normal man and in subjects with glomerulonephritis. J. Clin. Invest., 1938, 17, 347.

12. Peters, J. P., and Van Slyke, D. D., Quantitative clinical chemistry. Williams and Wilkins, Baltimore, 1931, Vol. I.

13. Smith, H. W., The Physiology of the Kidney. Oxford University Press, New York, 1937, p. 132.

14. Black, D. A. K., Urea clearance in haematemesis, Lancet, 1939, 1, 323

15. Smith, H. W., Goldring, W., and Chasis, H., The measurement of the tubular excretory mass, effective blood flow and filtration rate in the normal human kidney. J. Clin. Invest., 1938, 17, 263.

16. Van Slyke, D. D., and Cullen, G. E., Quantitative Clinical Chemistry. Williams and Wilkins, Baltimore, 1932, Vol. II, p. 547.

17. Smith, H. W., Personal communication to the authors.

18. Christiansen, $T$., Biochemical changes in the organism produced by massive intra-intestinal hemorrhage. Rev. Gastroenterol., 1937, 4, 166. 